\title{
65. Suppression of RNA Synthesis following Transferrin Removal in Chick Myotubes
}

\author{
By Akiko ShoJI and Eijiro OzAwA \\ Division of Cell Biology, National Center for Nervous, Mental and \\ Muscular Disorders, Kodaira, Tokyo 178 \\ (Communicated by Setsuro Ebashi, M. J. A., May 13, 1985)
}

Addition of chick transferrin (Tf) to basal culture medium (BCM) composed of $85 \%$ Eagle's minimum essential medium(MEM) and $15 \%$ horse serum is required for growth and differentiation of chick myogenic cells (Ozawa and Kohama, 1973, 1978; Kimura et al., 1982). In the presence of Tf, myotubes synthesized and accumulated various kinds of proteins (Hagiwara et al., 1981; Gerstenfeld et al., 1984; Ozawa et al., 1985), and accumulation of proteins resulted in myotube growth. Following Tf removal from the medium, large myotubes degenerated, becoming lean and flat, and their content of creatine kinase activity decreased. They were finally destroyed and detached from the culture dishes (Ozawa, 1977; Ozawa and Hagiwara, 1982). These morphological and biochemical analyses imply that there is disturbance in protein turnover in myotubes cultured under Tf-deficient conditions. In order to clarify the mechanism, we examined the metabolism of RNA and protein and found that their synthesis was greatly reduced following Tf removal.

Materials and methods. Procedures for preparation of chick myoblasts and purification of chick serum Tf were described elsewhere (Kimura et al., 1982). Myogenic cells (initial cell density: $2 \times 10^{6}$ cells/dish) were cultured in BCM containing $10 \mu \mathrm{g} / \mathrm{ml}$ chick Tf in $100 \mathrm{~mm}$ plastic culture dishes until the culture became almost confluent (9th day of incubation). On that day, experiments were started by changing the medium to the experimental and control media described below (day 0). DNA was measured by the method of Hinegardner (1971). Cytoplasmic RNA was isolated using guanidine hydrochloride as described by Chirgwin et al. (1979) and RNA content was determined by the orcinol method described by Brown (1946). RNA synthesis was determined assaying the amount of $\left[5,6-{ }^{3} \mathrm{H}\right]$ uridine (Amersham, $40-60 \mathrm{Ci} / \mathrm{mmol}$ ) taken into the TCA insoluble fraction as described by $\mathrm{Yu}$ and Frigelson (1971). Cells at various stages were labeled for $60 \mathrm{~min}$ with $2 \mu \mathrm{Ci} / \mathrm{ml}$ uridine. Total cytoplasmic RNA was sizefractionated with $1 \%$ agarose gel electrophoresis, according to the procedure of Macmaster and Carmichael (1977) and stained with ethidium bromide.

Results and discussion. Myotubes of 9 day culture were allowed to culture with control and experimental media for 4 more days. The control and experimental media were composed of BCM containing $10 \mu \mathrm{g} / \mathrm{ml} \mathrm{Tf}$ and BCM alone, respectively. Myotubes cultured with and without $\mathrm{Tf}$ are referred to as $\mathrm{Tf}(+)-$ and $\mathrm{Tf}(-)$ myotubes, respectively.

By day 4 after the medium switch, cells became flat in the $\mathrm{Tf}(-)$ myotubes. However, there was no obvious difference between DNA content on day 4 and the content on day 0 in the two myotubes. In contrast to DNA, total content of their cytoplasmic RNA, most of which was probably rRNA, decreased in both myotubes. In $\mathrm{Tf}(+)$ myotubes, the content decreased by about half of the initial 


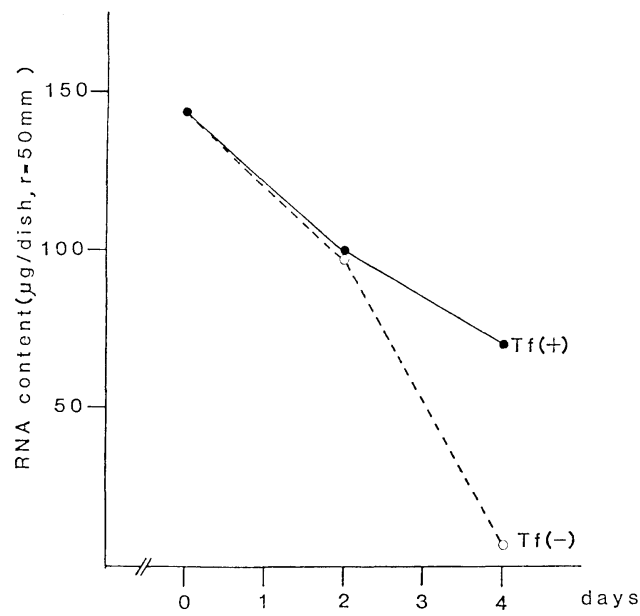

Fig. 1. Time course of RNA content in cultured myotubes. RNA content in $\mathrm{Tf}(+)$ myotubes and in $\operatorname{Tf}(-)$ myotubes $(O)$. Each point denotes the average of at least three dishes.

content by day 4 (Fig. 1). Decrease in the content in a confluent myogenic cell culture may be a natural course. In $\mathrm{Tf}(-)$ myotubes, however, the decrease rate after day 2 was faster and the content on day 4 was less than one-tenth of the initial content.

Synthetic rate of the total RNA in $\mathrm{Tf}(+)$ myotubes decreased a little with the lapse of time (Fig. 2). In $\mathrm{Tf}(-)$ myotubes, the rate began to decrease by $18 \mathrm{~h}$ after $\mathrm{Tf}$ removal, reached less than half of the initial rate on day 1, and decreased gradually thereafter. Degradation rates of the RNA did not greatly differ, although that in $\mathrm{Tf}(-)$ myotubes was a little faster (data not shown).

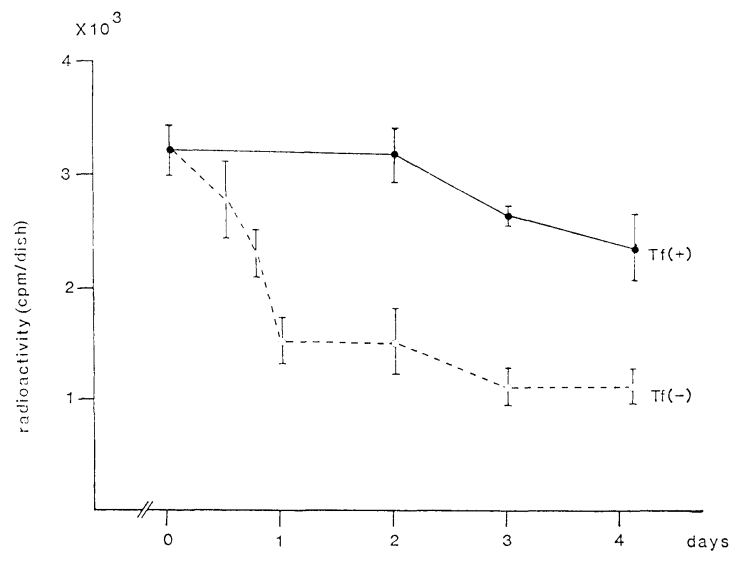

Fig. 2. Uptake of ${ }^{3} \mathrm{H}$-uridine into TCA insoluble fractions in $\operatorname{Tf}(+)$ myotubes $(\bullet)$ and $\operatorname{Tf}(-)$ myotubes $(0)$. Each sample was spotted on a filter paper, washed with cold TCA four times and counted in a toluene scintillator. No radioactivity remained on the filter when it was washed with hot TCA. 
We have observed that synthesis of myosin heavy chain and light chain $1 \mathrm{mRNA}$ was also reduced following Tf removal. RNA synthesis, especially total RNA synthesis, increased again after $\mathrm{Tf}$ readdition (data not shown). The results, however, differed between experiments. It is assumed that the reversibility depends on the grade of progress of degenerative process at the time of $\mathrm{Tf}$ readdition. It is clear that $\mathrm{Tf}$ influences RNA synthesis either directly or indirectly, and reduction in RNA synthesis is the main cause of reduced RNA content in $\mathrm{Tf}(-)$ myotubes.

The ratio of $28 \mathrm{~S}$ RNA to $18 \mathrm{~S}$ RNA was less in $\mathrm{Tf}(-)$ myotubes than in $\operatorname{Tf}(+)$ myotubes on day 2 (Fig. 3 ), suggesting that $\mathrm{Tf}$ removal did not affect all kinds of RNAs equally.

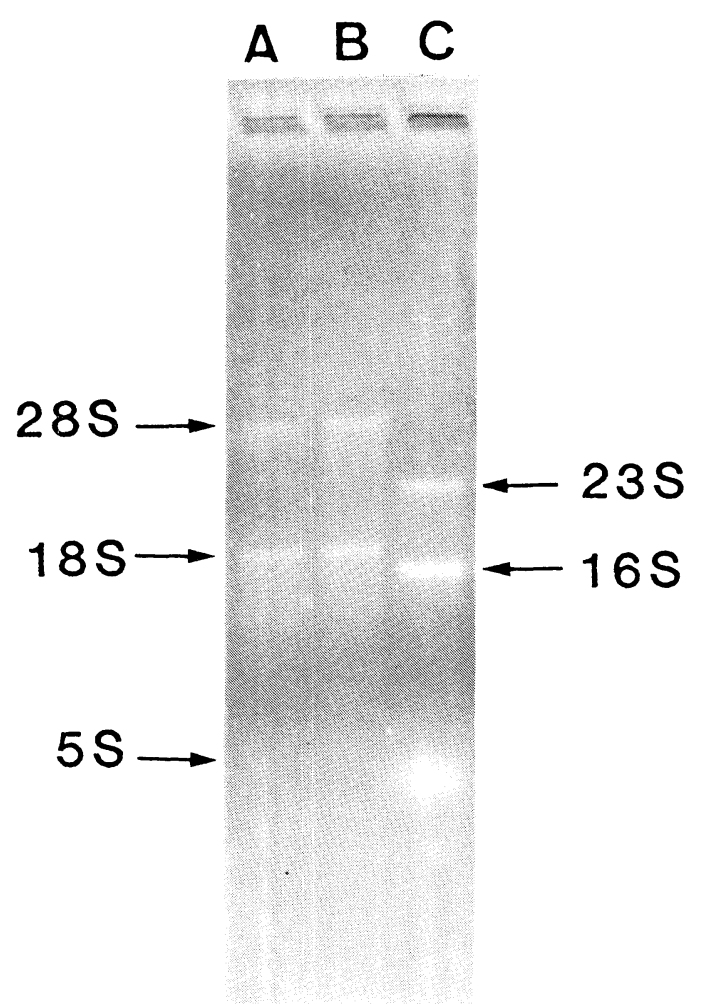

Fig. 3. Denaturating agarose gel electrophoretic patterns of RNAs. RNAs from (A) $\mathrm{Tf}(-)$ - and (B) $\mathrm{Tf}(+)$ myotubes on day 2. The same amount of RNA sample was applied to each lane. (C) RNAs from $E$. coli as an internal marker.

In addition to the disturbance in RNA metabolism, uridine uptake into cells was reduced following Tf removal (data not shown). However, it was clear from the time course study that reduction in the size of nucleotide pools due to the decreased uptake was not the sole cause of the decreased RNA synthesis. Under these conditions, protein synthesis was also affected in $\operatorname{Tf}(-)$ myotubes; for example, the rate was about two-thirds of that in $\mathrm{Tf}(+)$ myotubes on day 2 (data not shown).

We conclude that Tf removal from culture medium gives rise to a decrease 
in RNA synthesis of myotubes, which, in turn, results in a decrease in protein synthesis. This is responsible, at least partly, for degeneration of the myotubes.

Acknowledgments. We thank Dr. Y. Nabeshima for his providing us myosin light chain 1 cDNA. This work was partly supported by a grant from the National Center for Nervous, Mental and Muscular Disorders (NCNMMD 84-07) of the Ministry of Health and Welfare and a Grant-in-Aid for Special Project Research from the Ministry of Education, Science and Culture of Japan (Project no. 59113008).

\section{References}

Brown, A. H. (1946): Arch. Biochem., 11, 269.

Chirgwin, J. M. et al. (1979): Biochemistry, 18, 5294.

Gerstenfeld, L. C. et al. (1984) : Mol. Cell. Biol., 4, 1483.

Hagiwara, Y. et al. (1981): Develop. Growth Differ., 23, 249.

Hinegardner, R. T. (1971): Anal. Biochem., 39, 197.

Kimura, I. et al. (1982): Develop. Growth Differ., 24, 369.

Macmaster, G. K., and Carmichael, G. G. (1977) : Proc. Natl. Acad. Sci. USA, 74, 4835.

Ozawa, E. (1977) : Proc. Japan Acad., 53B, 130.

Ozawa, E., and Hagiwara, Y. (1982): Biomed. Res., 3, 16.

Ozawa, E., and Kohama, K. (1973) : Proc. Japan Acad., 49, 852.

- (1978): Muscle and Nerve, 1, 230.

Ozawa, E. et al. (1985): Molecular Biology of Muscle Development (eds. C. Emerson et al.). Alan, R. Liss, Inc., New York (in press).

Yu, F. L., and Frigelson, P. (1971): Anal. Biochem., 39, 319. 